\title{
La hegemonia revolucionaria en Bolivia: el MNR y La Revolución de 1952
}

\section{The Revolutionary Hegemony in Bolivia: The MIN and The Revolution of 1952}

\section{Juan Ignacio Estévez Rubin de Celis (iD}

Universidad Complutense de Madrid

juaest01@ucm.es

\begin{abstract}
Resumen
El presente trabajo es una aproximación al momento de emergencia del Movimiento Nacionalista Revolucionario (MNR) y a la posterior revolución nacional de 1952 en Bolivia. Desde una perspectiva posestructuralista se recurre al concepto de hegemonía elaborado por Ernesto Laclau y Chantal Mouffe, y de acá se deriva una amplia corriente de pensamiento político. Se parte de la hipótesis de que la construcción discursiva del MNR permitió romper la hegemonía sociopolítica del Estado oligárquico. Esta ruptura con el Estado adquirió carácter popular gracias a la articulación de demandas que excedian los intereses de quienes conformaban el MNR, incorporando también las demandas de los sectores subalternos de la sociedad, especialmente del campesinado y el proletariado minero. En este contexto, el sentimiento antioligárquico y el nacionalismo revolucionario se entienden como los significantes a partir de los que se impone una nueva hegemonía liderada por el MNR que se consolida con la Revolución Boliviana de 1952. El Estado ya se venía debilitando tras la Guerra del Chaco (1932-1935) y el posterior nacimiento del MNR en 1941.
\end{abstract}

Palabras clave: Hegemonía, Discurso, Revolución Nacional, Movimiento Nacionalista Revolucionario, Nacionalismo Revolucionario.

\begin{abstract}
This paper approaches the emergency of the Revolutionary Nationalist Movement (MNR) and the subsequent National Revolution of 1952 in Bolivia. From a post-structuralist perspective and resorting to the concept of hegemony elaborated by Ernesto Laclau and Chantal Mouffe-from which a broad current of political thought derives- the central hypothesis of the text understands that the discursive construction of the MNR's political project made possible to break with the sociopolitical hegemony of the oligarchic state. This rupture with the oligarchic state acquired a national and popular character thanks to the articulation of demands that exceeded the interests of those who conformed the MNR, such as those belonging to the subordinate sectors of society, especially the peasantry and the mining proletariat. In this context, the anti-oligarchic sentiment and revolutionary nationalism will be the signifiers to build this new hegemonic formation led by the MNR, and the Bolivian Revolution of 1952, the historical-political event that consolidates the process of decomposition of the oligarchic state that had begun after the Chaco War (1932-1935) and the subsequent birth of the MNR in 1941.
\end{abstract}

Keywords: Hegemony, Discourse, National Revolution, Revolutionary Nationalist Movement, Revolutionary nationalism.

Articulo: Recibido el 19 de octubre de 2018 y aprobado el 29 de octubre de 2019.

\section{Cómo citar este artículo:}

Estévez Rubín de Celis, J. I. (2019). La hegemonía revolucionaria en Bolivia: el MNR y La Revolución de 1952. Reflexión Política 21(43), pp. 23-35. doi: 10.29375/01240781.3419 


\section{Introducción}

El amor, el poder, la guerra. En eso consiste la verdad de la vida.Pues bien, fue en el Chaco, lugar sin vida,donde Bolivia fue a preguntar en qué consistía su vida.

Zavaleta, 1979, p.74

A partir del concepto de hegemonía elaborado por Ernesto Laclau y Chantal Mouffe y del que se deriva una amplia corriente de pensamiento que sigue a estos autores, este trabajo se aproxima de forma breve y sucinta al momento de emergencia del Movimiento Nacionalista Revolucionario de Bolivia y la posterior Revolución Nacional de 1952. La hipótesis de la que se parte es que la construcción discursiva del proyecto político del Movimiento Nacionalista Revolucionario permitió romper con la hegemonía sociopolítica del Estado oligárquico, ayudando a construir un proyecto nacional y popular. La Revolución boliviana de 1952 se entiende como el momento histórico y político que consolida la construcción de esta nueva hegemonía. Para que esto sea posible, se presta atención a la lógica política articulada por el Movimiento Nacionalista Revolucionario desde su nacimiento, en el año 1941, y cómo en este contexto se da una lucha por el sentido político, derivando finalmente en la Revolución Nacional de 1952. Para alcanzar estos objetivos, el trabajo consta de tres puntos centrales más unas conclusiones generales. El primer punto se centra en la aproximación teórica escogida, donde están recogidas las aportaciones más importantes de Mouffe y de Laclau, en materia de teorización con respecto al concepto de hegemonía. De esta forma, se pretende entender cuál es la lógica política que se articula en un momento y contexto determinados, permitiendo construir una nueva hegemonía política. En segundo lugar, una vez definido el concepto -junto a varios otros que ayudan al análisis-, se recurrirá a bibliografía principalmente historiográfica, además de sociológica y politológica que abarque la emergencia del Movimiento Nacionalista Revolucionario tras la Guerra del Chaco. Finalmente, se estudia la Revolución de 1952, entendiéndola como el parteaguas definitivo entre la articulación de una nueva hegemonía política y, por otro lado, la consolidación del Estado postoligárquico o Estado revolucionario/nacional-popular. El último apartado está dedicado a recoger algunas conclusiones y reflexiones generales.

\section{Conceptualización: construir hegemonia}

La Teoría de la Hegemonía, anclada en la Teoría del Discurso Político de la Escuela de Essex, es una tradición de pensamiento político conocida como posmarxista, posestructuralista o posfundacional ${ }^{1}$. Esta teoría se articula asumiendo dos postulados básicos; a saber: a) que todo orden social es una construcción que se estructura dentro de un campo discursivo; es decir, que no hay nada fuera del discurso ${ }^{2}$; y b) que, a partir de una deconstrucción de las categorías centrales de la teoría marxista, la crítica al racionalismo behaviorista y de la recepción de conceptos provenientes de otras disciplinas, se adopta una postura antiesencialista a la hora de entender y estudiar la construcción de lo social y las identidades; es decir, se entiende que "la sociedad y los agentes social carecen de esencia” (Laclau \& Mouffe, 2015, p.134) ${ }^{3}$. De estos postulados se desprende un tercero que en cierto sentido les es implícito, y tiene que ver con la concepción de lo social y lo político como una pluralidad abierta y carente de un fundamento unitario último; por ello que los autores

${ }^{1}$ Como señala Barrett (2004, p.274) a la hora de referirse a la obra de Laclau, la calificación de "posmarxista" viene dada porque su empresa teórica supera los problemas teóricos del marxismo, pero no los resuelve. En este sentido, el problema teórico no puede ser resuelto porque no sería teórico, sino empírico; ya que un problema teórico implica una incoherencia en la estructura lógica de la teoría que no puede ser resuelta, sino superada.

${ }^{2}$ Laclau y Mouffe ejemplifica está afirmación diciendo que "un terremoto o la caída de un ladrillo son hechos de cuya existencia no dudamos porque ocurren aquí y ahora, independientemente de mi voluntad. Pero, que su especificidad como objetos se construya en términos de 'fenómenos naturales' o de 'expresión de la ira de Dios', depende de la estructuración de un campo discursivo". Es decir, que niegan la posibilidad de que un objeto social pueda constituirse al margen del discurso (Laclau \& Mouffe, 2015, p. 147). En este sentido, resulta muy útil la aclaración que hace Paula Biglieri a la hora de referirse al principio ontológico de concebir lo social como un espacio discursivo. Así, siguiendo a Laclau, dirá que "su concepción del discurso excede la mera noción lingüística, ya que no solo refiere al discurso como habla o palabra escrita, sino como toda relación de significación" (Biglieri, 2011 , p. 96). Para una revisión en profundidad acerca de la noción de discurso posestructuralista que utilizamos en este texto, véase la obra de Howarth (2000, 2005) y Howarth, Norval y Stavrakakis (2000).

${ }^{3}$ La rotundidad de su crítica antiesencialista podría condensarse en la siguiente afirmación que hacen los autores a la hora de referirse a la construcción de una teoría de los social: “Un enfoque 'científico' que intentara determinar la 'esencia' de lo social sería el punto álgido del utopismo" (Laclau \& Mouffe, 2015, p.187). 
asumen que, para estudiar lo social o lo político, "la pluralidad no es el fenómeno a explicar, sino el punto de partida del análisis” (Laclau \& Mouffe, 2015, p.184). A partir de estos pilares de aproximación teórica al estudio de lo social, se recurre al concepto de hegemonía elaborado por los autores citados y, al mismo tiempo, a aquellos conceptos a partir de los cuales se construye y se entiende la lógica de construcción de una hegemonía política a la hora de referirse a la emergencia del Movimiento Nacionalista Revolucionario (MNR) y la Revolución Nacional de 1952 en Bolivia (RN).

En la argumentación previa a la conceptualización de la hegemonía que llevan a cabo estos autores, el concepto de antagonismo aparece como dispositivo elemental a la hora de construir un nuevo orden social. El antagonismo no es algo que está más allá de lo social -como si de una frontera objetivable y fija se tratara-, sino que se da en el seno de lo social y lo subvierte evitando la aspiración de lo social de constituirse como una totalidad plena y cerrada (Laclau \& Mouffe, 2015, pp. 164-170). En otras palabras, el antagonismo equivale a la noción de una frontera que divide la sociedad en dos campos estructurados (Laclau, 2005, p. 110). En la medida en la que el antagonismo no viene dado per se, este debe ser construido por medio de la articulación ${ }^{4}$ de una serie de demandas sociales ${ }^{5}$, lo que equivale hablar de una "regularidad en la dispersión", dotando de sentido y significado al conflicto en una sociedad determinada. A esta lógica de articular demandas sociales se la denominó "lógica de la equivalencia" y es la que permite trazar una frontera radical en lo social, construyendo dos polos antagónicos y, al mismo tiempo, una nueva subjetividad (popular). Por lo tanto, y de acuerdo con Biglieri (2011), que prevalezca una relación de equivalencia entre una pluralidad de demandas sociales, permite establecer una frontera antagónica entre un "nosotros" y un "ellos" al que se identificará como el enemigo o adversario (p.97). En el planteamiento que ofrecen los autores, es importante tener en cuenta que en toda sociedad se dan múltiples antagonismos de los que surgen luchas democráticas, como puedan ser las luchas antirracistas o las feministas pero, si bien son importantes, al mismo tiempo son luchas secundarias porque para ellos lo realmente importante es una lucha radical por la "toma del poder" en el sentido clásico, y ello es posible en la medida en la que se traza una frontera antagónica radical que divida el espacio político en dos campos nítidamente diferenciados (Laclau \& Mouffe, 2015, p.175). Por esto la idea de articulación, entendida como una suerte de "práctica que establece una relación entre elementos de tal forma que su identidad resulte modificada como resultado de la práctica articulatoria" (Barrett, 2004, p.278), es tan importante a la hora de entender la construcción del antagonismo.

Hay que recordar la importancia que tienen los conceptos de articulación y antagonismo a la hora de pensar en la construcción de una hegemonía política. Asumir que es posible articular una serie de demandas a través de una cadena equivalencial que resulte en dos polos antagónicos implica asumir que la sociedad no está cerrada, que no existe ninguna lógica unitaria que permita una unificación de lo social. "La hegemonía solo puede constituirse en un campo dominado por prácticas articulatorias porque requiere un carácter incompleto y abierto de lo social" (Laclau \& Mouffe, 2015, p.178). Por lo tanto, para poder construir hegemonía se deben presentar dos fuerzas antagónicas, una articulación de demandas equivalencia- que produzca una nueva subjetividad $y$, finalmente, una inestabilidad en la frontera que separa a los polos antagónicos.

Cabe, por último, presentar una definición de hegemonía o, si se quiere, de formación hegemónica. Es bien sabido que Laclau y Mouffe desarrollaron su teoría acerca de la hegemonía teniendo como referencia inmediata y más avanzada a la tesis que Gramsci había propuesto en torno al mismo concepto, motivo por el cual autoras como Barrett entienden que Laclau y Mouffe ven en la figura de Gramsci el punto crucial entre el marxismo y una teoría política viable (Barrett, 2004, p.263). "[Para Gramsci] la hegemonía es mejor comprendida como la organización del consentimiento: el proceso que construye formas subordinadas de conciencia sin recurrir a la violencia o la coerción" (p.266). Se trata de comprender que para Gramsci la hegemonía se fundamenta en la consecución de una voluntad

${ }^{4}$ A pesar de que en su obra dedican un buen número de páginas a teorizar en torno al concepto de articulación, más adelante los autores darán una definición más sencilla, planteando que es "una práctica de instituir puntos nodales que fijan parcialmente el sentido de lo social en un sistema organizado de diferencias" -entendiendo por puntos nodales aquellos significantes privilegiados que van fijando el sentido en una cadena de significantes- (Laclau \& Mouffe, 2015, pp. 152, 179).

${ }^{5}$ En La razón populista (2005), Laclau plantea que la unidad mínima de análisis corresponde a la categoría de "demanda social". Estas serán divididas entre "demandas democráticas", entendidas como aquellas que, satisfechas o no, permanecen aisladas; y, por otro lado, las "demandas populares", entendidas como aquellas que son articuladas a través de una equivalencia, constituyendo una subjetividad social más amplia (Laclau, 2005, pp. 97-99). 
colectiva. Sin embargo, la perspectiva de análisis de Gramsci es esencialista, en última instancia, y lo es con respecto a la posición privilegiada que otorga a la clase trabajadora; y lo es también con relación al último reducto del esencialismo: la economía (p.276).

Si se toma por válida una definición mínima de hegemonía gramsciana entendida como la consecución de una voluntad colectiva ${ }^{6} \mathrm{y}$, por otro lado, esta es despojada del esencialismo propio de la tradición marxista que también está presente en Gramsci, se tiene como resultado la noción de hegemonía que aportan Laclau y Mouffe, pero en especial por el primero, en una obra posterior a Hegemonía y estrategia, en la que definirá hegemonía como la posibilidad de que un sector de la sociedad, una particularidad, "pueda presentar sus objetivos propios como aquellos que hacen posible la realización de los objetivos universales de la comunidad" (Laclau, 2011, p.57). Así, la articulación entre universalidad y particularidad es igual a la victoria hegemónica, y ello significa que una "fuerza social particular asume la representación de una totalidad que es radicalmente inconmensurable a ella" (Laclau \& Mouffe, 2015, p.9). No se trata de entender esta identificación como un proceso de alienación o una manipulación demagógica, sino como la posibilidad de que un sector de la sociedad se muestre capaz de derrotar al otro-antagónico (Laclau, 2011, p.61). Por ejemplo, en el caso del MNR, que se estudiará más adelante: si de la hipótesis se desprende la idea de que el MNR se convierte en esa parte de la sociedad que, si dejar de ser una parte, una particularidad, asume la representación de una universalidad más amplia, de un conjunto de particularidades, es porque se ve capaz de encarnar la derrota del otro-antagónico, que es acá la "Rosca Minera" 7 o el Estado oligárquico. De ser así, se estaría haciendo referencia a la construcción de una nueva hegemonía política. Así, el MNR y quienes protagonizan el episodio revolucionario deben ser entendidos como sujetos políticos construidos políticamente a través de la equivalencia de una pluralidad de demandas.

En la medida en que se tiene una noción medianamente clara del concepto de hegemonía y de la forma en que se articula una formación hegemónica, se recurre a un último concepto que resulta de vital importancia: la producción de significantes vacíos. Cuando se habla de hegemonía como una operación por la que una particularidad asume una significación universal, se hace referencia a la lógica política que permite la construcción de una nueva subjetividad, es decir, de la construcción de la narrativa de un nuevo "yo colectivo" respecto de un otro, de un afuera constitutivo. Así, ese exterior "no es un elemento más, neutral, sino resultado de una exclusión" (Laclau, 2005, p.81) y por ello que se convierte en el enemigo, y en tanto enemigo, se convierte en el principio unificador de los eslabones o particularidades que forman parte de la cadena de equivalencia y lo hace a través de un significante vacío. Por tanto, el significante vacío, unifica la cadena de equivalencias. La relación hegemónica "requiere la producción de significantes tendencialmente vacíos que, mientras mantienen la inconmensurabilidad entre el universal y los particulares, permite a estos últimos asumir la representación del primero" (Laclau, 2011, p.64). Así, se puede asumir que, en el contexto revolucionario de 1952, el enemigo se representa a través del significante vacío "rosca minera". La producción de significantes vacíos como "pueblo", "oligarquía" o "rosca minera" es una particularidad que aspira a rellenar una universalidad, que en este contexto debe ser entendida como algo vacío. Concibiendo así a la universalidad, la operación hegemónica consiste precisamente en dotarla de contenido, de construirla. La lógica del significante vacío es, en consecuencia, la lógica de la autonomía del significante con respecto al significado. $\mathrm{Si}$, por ejemplo, el concepto/significado "pueblo" hace referencia a la totalidad de individuos que forman parte de la comunidad política conocida como nación, el desplazamiento del significante con respecto al significado permitiría que el pueblo sea articulado como un significante vacío que, en este caso, representaría a una comunidad de individuos que se identifican como "el auténtico pueblo" con respecto a un afuera constitutivo/enemigo y que, si bien en términos formales forman parte de esa comunidad política que es la nación, pasan a ser el "anti-pueblo" o, en este caso, "la rosca minera".

\footnotetext{
${ }^{6}$ Téngase en cuenta que Para Laclau y Mouffe la voluntad colectiva se construye a partir de posiciones particulares que son articuladas en una cadena de equivalencias. Es decir que, al no ser entendidas como posiciones de clase, como sí ocurre en la teoría gramsciana, no se asumen como posiciones predeterminadas. En otras palabras, no existe un anclaje identitario último que venga dado por una totalidad suturada, por una determinación estructural (Laclau \& Mouffe, 2015, p.180).

7 "La rosca" es la expresión por medio de la cual se identificaba a las élites políticas y económicas de Bolivia. También fueron conocidos como "patriarcas de la plata" o "barones del estaño". Esta rosca estaba conformada por un grupo reducido de empresarios que controlaban prácticamente la totalidad de la actividad minera boliviana.
} 


\section{La emergencia del MNR: antecedentes históricos}

La problemática que en este apartado se trata tiene que ver con la emergencia del Nacionalismo Revolucionario (NR), entendido como el umbral discusivo (Laclau, 2013) a partir del cual se articulará el poder del Estado en Bolivia tras conflicto bélico entre Paraguay y Bolivia conocido como la "Guerra del Chaco"8. La Guerra del Chaco es considerada por autores como Llobet (1984) como el acontecimiento que "transformaría la sociedad boliviana, convirtiéndose en el punto de partida de la historia contemporánea de Bolivia", no tanto por la importancia militar, sino por "su inmenso poder catalizador político y social” (p.320). Bolivia hasta entonces había sido, sin lugar a dudas, un "país que no ha[bía] resuelto sus problemas de integración nacional. Que mantiene a la mayoría de su población en la opresión generalizada, el exilio político y la ignorancia" (Zavaleta, 1979, p.83). Ante la realidad socio-política del país, y siendo escuetos en el argumento, se puede aseverar que la Guerra del Chaco se convirtió en el acontecimiento político por medio del cual se inauguró un relato nacional capaz de convocar a la causa bélica a los sectores sociales que hasta entonces habian permanecido en la periferia del imaginario social y político. Al mismo tiempo, se trata del acontecimiento político que produce "la desorientación del poder oligárquico que ya no retomará su coherencia; es aquí donde comienza su decadencia" (p.85). Es decir, que la Guerra del Chaco supone el punto de partida del fracaso definitivo de la hegemonía liberal económica y política de la minería del estaño. Así, quienes participaron en la contienda fueron, sobre todo, el proletariado de la minería, el campesinado, los jóvenes militares y los pequeños sectores de una inminente burguesía urbana artesanal, además de estudiantes y maestros. En sentido contrario, los ausentes en el conflicto fueron los sectores que dominaban la escena política y económica: la burguesía minera exportadora, los terratenientes y el alto mando militar (Llobet, 1984, p.321). Esta fragmentación entre el bloque de poder del Estado oligárquico -constituido por la gran minería, los latifundistas y altos mandos militares- y las nacientes organizaciones nacionalistas de base popular -proletariado minero y campesinos, sectores jóvenes del ejército y los nuevos sectores urbanos- muestra que el espacio social boliviano empezaba a dicotomizarse, mostrando la frontera que más tarde separaría a la oligarquía del pueblo9.

La Guerra del Chaco hará que la "nación" se convierta en el leitmotiv de cualquier proyecto social o político que pretenda construirse en Bolivia. Es decir que, después de incluir en la narrativa colectiva a los sectores históricamente excluidos -quienes, además, aceleran el proceso de empoderamiento político iniciado décadas atrás ${ }^{10}$, el objetivo político es el de construir la Nación boliviana. La guerra, en definitiva, "había creado las tendencias subjetivas para la construcción de la unidad nacional y del estado nacional (...) ly, en consecuencia] los elementos subjetivos de la nacionalización preceden siempre a la formulación

Tabla 1. Distribución antagónica de actores en el contexto de la Guerra del Chaco y la crisis del Estado oligárquico.

\section{Pueblo \\ Oligarquia}

Nuevos sujetos políticos enfrentados al bloque de poder

Bloque de poder del Estado oligárquico

- Proletariado minero

- Campesinado

- Jóvenes militares

- Inminente burguesía urbana

- Estudiantes

- Burguesía

minero-exportadora

- Maestros

- Terratenientes-latifundistas

- Alto mando militar

Fuente: Elaboración propia a partir de los datos recogidos en Llobet (1984) y Dunkerley (1984).

${ }^{8}$ Un relato detallado, cargado de subjetividad y no muy extenso de la experiencia de la Guerra del Chaco puede verse en la obra de Víctor Andrade quien vivió en primera persona la trasformación que sufrió Bolivia tras la guerra y quien más tarde participó en los gobiernos de Villarroel, Estenssoro y Zuazo (1979, pp.15-25).

${ }^{9}$ Si bien es la Guerra del Chaco el acontecimiento histórico que da inicio a la decadencia del bloque de poder en Bolivia, una lectura más amplia y en perspectiva regional como la que ofrece Dunkerley (1984) entiende que la política de masas en Bolivia se inicia en la década de 1930 en un contexto regional del que el país no es ajeno y que, de una u otra manera influyen en el proceso de acumulación política de masas en que sobre todo destaca la influencia del Cárdenas en México, Getulio Vargas en Brasil o el Frente Popular en Chile.

10 Según relata Llobet, la transición de la plata al estaño como principal producto de exportación en una economía caracterizada por ser primarioexportadora, supone el crecimiento del sector minero, lo que permitió, a su vez, un crecimiento del proletariado vinculado directa e indirectamente a la minería que durante las primeras décadas del siglo llevará a cabo intentos de sindicalización obrera con relativo éxito. Las experiencias más importantes serían las de la Federación Ferroviaria de Oruro, el Primer, Segundo y Tercer Congreso Nacional de Trabajadores, la Central de Mineros de Uncía, entre otras. Asimismo, serán décadas de crecimiento de los sectores urbanos, sobre todo artesanos, pequeños comerciantes y profesiones liberales, es decir, una incipiente pequeña burguesía urbana (Llobet, 1984, pp. 312-320) 
objetiva de tales tareas" (Zavaleta, 1979, p.87, énfasis añadido). Estos elementos subjetivos se refieren a los procesos de identificación que se están dando en el seno de lo social y que más tarde derivarán en la articulación de una nueva formación hegemónica. Entender que la lógica política desde entonces pasaría por construir la nación, que ahora deviene en popular, implica asumir dos hechos clave: a) que la élite política y económica, hasta entonces hegemónica, no sería capaz de encarnar el nuevo proyecto a construir; y b) que la disputa política entre los actores políticos protagonistas del momento implicaba definir quién o qué sector de la sociedad dotaría de sentido a los nuevos significantes -antiimperialismo y antioligarquía en el sentido de lo nacional y popular-surgidos tras la desastrosa guerra.

El MNR supone una respuesta a la crisis ideológica del Estado oligárquico - “se trata del fracaso del poder articulatorio de la ideología liberal" (Antezana, 1983, p.64)- y a su vez, debe enmarcarse como un actor político más en una constelación mucho más amplia. Junto al MNR emergerán otros partidos que desarrollaran, al igual que este, "interpelaciones populares y antioligárquicas; (...) y el campo de disputa discursiva tendrá dos nuevos interlocutores: la clase obrera y los indios" (Mayorga, 1985, p.61). Estas nuevas formaciones serán el Partido de la Izquierda Revolucionaria (PIR), el Partido Obrero Revolucionario (POR) y la Falange Socialista Boliviana (FSB). Se trata de partidos que provienen de tradiciones políticas dispares; desde el trotskismo, pasando por el marxismo, el fascismo o el nacionalismo. Cada uno de estos partidos se entiende como consecuencia de un régimen que se derrumba y, por tanto, que las interpelaciones que lleven a cabo responderán a la emergencia, siguiendo a Laclau, de nuevas demandas populares surgidas desde las capas sociales subalternas.

Centrando el foco en el caso del MNR, este se fundará seis años después de la guerra, en 1941, por un grupo de socialistas independientes vinculados a la publicación La Calle. Su objetivo era "promover un movimiento patriótico de orientación socialista, dirigido a defender y afirmar la nacionalidad boliviana" (citado por Llobet, 1984, p.325). De esta forma, el MNR será el movimiento que canalizará hacia sí "las derivaciones sociales de la decadencia del estado oligárquico (...) [congregando] en su seno a las nuevas zonas clasistas que ingresarán en la política, es decir, a los obreros y a los campesinos" (Zavaleta, 1979, p.89). El movimiento, entonces, se convierte en el partido político que encarna la necesidad de ruptura en el orden de lo social, permitiendo construir la frontera antagónica que divide el espacio social boliviano entre un "nosotros" y un "ellos/oligarquía", y lo hace a través de la articulación de una serie de demandas particulares pertenecientes a diversos sectores, entre ellos el movimiento obrero (minero), el campesinado y una parte del ejército.

El hecho de que el MNR -y no el PIR, el POR o la FSB- se haya convertido en una influencia política tiene que ver, entre otros factores, con los postulados políticos e ideológicos de los demás partidos. En este sentido, para partidos como el POR o el PIR el sujeto político al que debían dirigirse era la clase obrera, excluyendo a otros sectores como el ejército; mientras que el problema de la FSB era su carácter de patriotismo hispanizante, que encajaba mal en un país con una población indígena tan grande. Por el contrario, el MNR, de origen pequeñoburgués, estaba compuesto jóvenes políticos y empresarios provenientes de las familias poderosas que ya no creían en la viabilidad de un proyecto oligárquico; también por excombatientes de la guerra, lo cual le permitía tender puentes con los jóvenes oficiales nacionalistas; $\mathrm{y}$, finalmente, por el proletariado minero ${ }^{11}$ gracias a que fue, en efecto, el único partido que denunció la masacre en la mina de Catavi en $1942^{12}$. En consecuencia, el MNR, que desde su creación había desarrollado una interpelación nacionalista dirigida a un sujeto interclasista, devino en el partido que mejor encarnaba y, por tanto, representaba el denominado nacionalismo revolucionario. Para Antezana, el NR será el relato que englobe a tendencias políticas tan dispares como el socialismo, nacionalismo, indigenismo, antiimperialismo o el fascismo; pero que, tras la Guerra del Chaco, vira "aceleradamente

\footnotetext{
${ }^{11}$ Con respecto de la participación en el proyecto del MNR por parte del proletariado minero, Zavaleta (1979, pp.88-89) apunta a dos escenarios distintos: en primer lugar, advierte que el sector minero, de forma consciente o inconsciente, utilizó a los políticos del MNR para ingresar en la política; pero, por otro lado, señala las intenciones que tenía el partido de organizar al movimiento obrero en aras de buscar un equilibrio entre obreros y militares, de cara a sus adversarios. Esta reflexión conduce a cuestionar si, en lugar de ser el MNR el sujeto articulador de la nueva hegemonía, hipótesis sobre la que se asienta el presente texto, lo fue el movimiento obrero minero. Tal discusión ameritaría un trabajo dedicado exclusivamente a esta cuestión.

12 Tras la muerte del presidente Germán Busch en extrañas condiciones, se produce una restauración oligárquica que más tarde fue contestada con una huelga en el complejo minero de Catavi, propiedad del importante empresario minero Simón I. Patiño. La huelga se saldará con la detención de los principales dirigentes convocantes y cuando los mineros y sus familias se dirigen a las oficinas administrativas de la empresa son atacados por un destacamento militar con un saldo de más de 400 muertes (Llobet, 1984, pp.324-325).
} 
hacia el centro del poder estatal" convirtiéndose en una suerte de "puente tendido entre los extremos del espectro político boliviano" (Antezana, 1983, p.61). Es decir, que el nacionalismo revolucionario se convierte en el umbral de la política; lo único a través del cual se puede aspirar a ejercer el control político.

Ahora bien, ¿cuál es el vínculo entre el nacionalismo revolucionario y el MNR? Y ¿por qué? Siguiendo la argumentación que lleva a cabo Antezana (1983, pp.65-67), quien se vale de la obra de Montenegro, considerado por muchos el teórico del MNR e ideólogo del NR (Antezana, 1983; Llobet, 1984; Mayorga, 1985; Zavaleta, 1979), la construcción del nacionalismo se fundamenta, por una lado, en la recuperación de la idea de nación a la que ahora se dota de un nuevo contenido: la nación, históricamente dominada por el yugo colonial español y luego oligárquico, pasa a ser identificada con el pueblo y, por extensión, como un segundo proceso de liberación de cualquier forma de dominación colonial. Asimismo, la oligarquía pasa a ocupar el rol de detractora de la nación y ello implica una asociación directa entre oligarquía, antinación, antipueblo y antiimperialismo. La lucha nacional, que se entiende como antioligárquica y antiimperialista, sufre un proceso de torsión que la vincula con la segunda pata del umbral discursivo: la revolución. Así, si la idea de nación se asocia a sectores más bien conservadores que ponen ciertas resistencias a asumir que campesinos, indígenas $\mathrm{u}$ obreros mineros formen parte de la idea de pueblo. Así, el NR encontró en la revolución el significante articulador de las demandas provenientes de la izquierda marxista, convirtiéndola en una "izquierda nacional".

Este nacionalismo revolucionario será construido desde distintos sectores de la sociedad, uno de ellos el sector del ejército que, tras la guerra, sufre un proceso de dislocación de las identidades políticas sobre las que se sostenía (Barros, 2002). Este sector del ejército era reconocido bajo el rótulo de socialismo militar, del que derivó la

Logia militar RADEPA (Razón de Patria), formada por "oficiales jóvenes que concurrieron a la Guerra del Chaco y que se habían distinguido por sus condiciones de mando, sacrificio y valor personal" (Andrade, 1979, p.37). El antecedente de RADEPA estuvo en los gobiernos militares inspirados en el socialismo militar de David Toro (1936-1937) y Germán Busch (1937-1939). El gobierno de estos militares se desarrolló ante la ausencia de una articulación discursiva que pudiese disputar el sentido político a la hegemonía liberal (Mayorga, 1985, pp.64-66), lo que derivó en que, tras la desaparición física de Busch, se diese una restauración oligárquica. No obstante, lo realmente importante era constatar que en el seno de las fuerzas armadas se reflejaba el "hartazgo de los viejos esquemas políticos y la necesidad de su sustitución por elementos que incubaron la idea nacional" (Llobet, 1984, p.323).

Pero ¿qué puede esperarse de un grupo de militares que invocan la Razón de Patria como única razón de sus acciones ante un relato histórico que se ancla en el sentimiento de la derrota y la humillación? Convertirse en un grupo militar destinado a eliminar a los enemigos de la patria donde, además, son ellos quienes definen el concepto de patria. Afortunadamente para quienes simpatizan con la gesta revolucionaria, y lamentablemente para quienes no lo hacen, RADEPA identifica a la oligarquía -en lugar de, por ejemplo, al comunismo-, como responsable de la humillación del Chaco, como los enemigos de la patria. Por ello es muy importante entender el rol articulador que tuvo el MNR entre distintos sectores de la sociedad, entre ellos los jóvenes militares de RADEPA. Como señala Llobet, el encuentro entre el MNR y RADEPA derivó en que estos últimos, enemigos de la oligarquía y la antipatria, despertasen una importante sensibilidad social, lo que permitió que comprendieran "que en la nueva fase de la historia nacional las masas obreras iban a jugar un papel de primera importancia” (Llobet, 1984, p.324).

Es así como se tejió la alianza entre el MNR, que por entonces tenía representación parlamentaria a través de la figura de dos futuros líderes históricos del MNR -Víctor Paz Estenssoro y Hernán Siles Zuazo- y RADEPA en 1943. Este pacto de rebelión derivó en la llegada al poder del MNR con el joven militar proveniente de RADEPA, Gualberto Villarroel, como presidente, además del líder del MNR, Paz Estenssoro como ministro de hacienda (Llobet, 1984, p.325). Este primer gobierno, aunque más tarde fracasó, contó con una adhesión entusiasta de diversos sectores, pero en especial de los obreros mineros y campesinos debido a las medidas de modernización tributaria que se aplicaron sobre la minería o la supresión del pongueaje, que es como se conocía al trabajo 
gratuito para el terrateniente (Zavaleta, 1979, p. 89). Esta adhesión entusiasta de los sectores mineros y campesinos es de especial trascendencia en la medida en la que se empieza a observar que el MNR, entendido como una particularidad más, es capaz, de acuerdo con la lógica hegemónica, de presentar sus objetivos propios como aquellos que hacen posible la realización de los objetivos de un conjunto más amplio, de una universalidad. Asimismo, este hecho pone de manifiesto las resistencias y problemas que empezaban a tener los partidos de clase como el POR, pero en espacial el PIR, para representar las demandas de los sectores mineros. En esta línea se expresa Lora (1983, p.172) cuando plantea que el MNR empezó a enarbolar las consignas de clase del POR, pero vaciándolas de su contenido revolucionario de clase y llenándolas de un contenido burgués o interclasista, lo que equivale a hablar de una victoria en la lucha por el sentido de las consignas políticas que interpelaban a los sectores obreros. Sin embargo, el gobierno de Villarroel, que había iniciado unas tímidas, pero efectivas reformas, terminó de forma trágica ${ }^{13}$, acusado de alineamientos con el Eje, de postulados protofascista o protonazis, de enemigos de la democracia ${ }^{14} y$, en consecuencia, de que el gobierno de EEUU no reconociera al gobierno de Villarroel, con todo lo que eso conlleva en un país como Bolivia. Como señala Zavaleta con gran lucidez:

\begin{abstract}
Los reformadores, en todo caso, no pueden ser moderados, porque sus reformas, no importa si moderadas o no, son interpretadas siempre por la clase dominante como un reto total; por tanto, es mejor ir más lejos de donde se quiera ir porque desde allá se puede retroceder hasta donde se quería llegar. (Zavaleta, 1979, p.90)
\end{abstract}

Aunque sí se dio la alianza MNR-RADEPA, lo cierto es que para RADEPA el MNR podía llegar a suponer una necesidad, pero a la vez un estorbo. Por esto el movimiento, con un proyecto más concreto que el de la venganza y la razón de patria, tenía que intentar organizar a los obreros y lo conseguiría haciendo que Juan Lechín Oquendo, antiguo trabajador minero, fuera nombrado subprefecto de Uncía, el centro de la principal concentración minera. Cuando Lechín solicita una reunión con el gerente de la principal mina, la Patiño Mines, y obtiene por respuesta que la reunión, en caso de celebrarse, debía hacerse en las oficinas de la gerencia de la mina, Lechín ordena su arresto y es así como sentencia su victoria sobre todo el sindicalismo anterior a él (Zavaleta, 1979, pp.9293). A esta exitosa operación se deben sumar los fracasos de la izquierda marxista del PIR que, en su afán de organizar y dirigir al movimiento obrero, se convirtió en uno de los instrumentos de la oligarquía al formar parte del Frente Antifascista y asumir que el gobierno de Villarroel era un gobierno fascista. El resultado fue que la oligarquía aliada a la izquierda marxista consiguió movilizar a sectores estudiantiles y populares para colgar de un poste de alumbrado público de la plaza Murillo a Villarroel y a sus colaboradores, dejando en adelante el camino expedito para que sea el MNR quien encarne la lucha obrera y campesina (Llobet, 1984, p.328; Zavaleta, 1979, p.94). En consecuencia, la oligarquía se convertía en el enemigo común; en el eslabón que unía la cadena de equivalencias que se estableció entre el ejército, los sectores que englobaba el MNR, el movimiento obrero minero y el campesinado. Nada de esto significa que cada sector haya perdido su particularidad: RADEPA siguió defendiendo su razón de patria ante una oligarquía responsable de la humillación de la patria en la guerra, mientras que el movimiento obrero y el campesinado siguieron defendiendo su lucha por el fin de la explotación de esa misma oligarquía, pero ahora sin un partido de clase en la vanguardia. La oligarquía y el nacionalismo revolucionario pasaron a ser aquellos elementos por medio del cuales se empezó a identificar cierta regularidad dentro de las diferencias que existían en esta diversidad de actores- El espacio social empezó a presentarse a través de dos fuerzas antagónicas y la equivalencia de demandas producía una nueva subjetividad colectiva. No obstante, la frontera antagónica era aún demasiado inestable y el régimen oligárquico agonizaba pero no estaba muerto. Prueba de ello es el ahorcamiento de un presidente indudablemente popular, por lo que en este punto todavía no se puede hablar de la consolidación de una nueva formación hegemónica.

\footnotetext{
${ }^{13}$ La muerte de Villarroel, colgado en la plaza enfrente al Palacio de Gobierno, puede ser interpretada como el último intento de la oligarquía de romper la lógica de equivalencia que en aquel momento se estaba construyendo. Es un hecho que ni RADEPA ni el MNR tenían la intención de romper el Estado, sino que buscaban su modernización. No obstante, la muerte de Villarroel suponía para la oligarquía la forma más efectiva de dividir cada una de esas reivindicaciones que se iban articulando en el polo popular.

${ }^{14}$ En sus memorias, Andrade recuerda cómo se vivió desde el gobierno la ofensiva diplomática llevada a cabo desde EEUU, al tiempo que reproduce de forma íntegra el famoso Memorándum enviado por el Secretario de Estado, Cordell Hull, a sus principales Embajadas en Sur América, en el que se advierte sobre los peligros del gobierno MNR-RADEPA (Andrade, 1979, pp.41-54).
} 
Figura 1. Estructuración del campo discursivo en la lucha por la hegemonía en Bolivia antes de la Revolución de 1952.

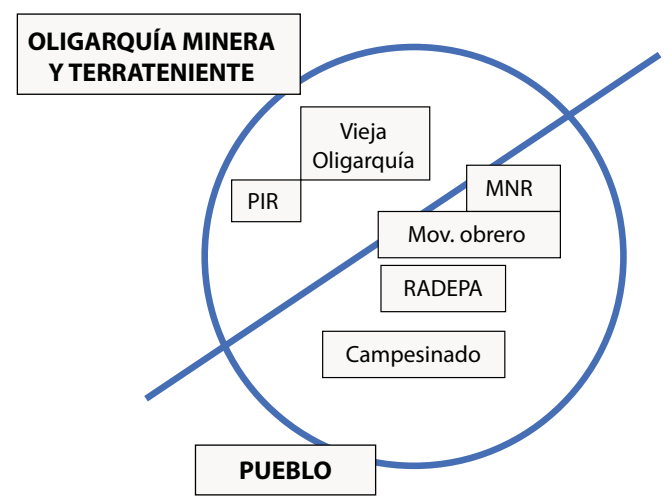

Fuente: Elaboración propia.

\section{La Revolución Nacional de 1952}

La hipótesis sobre la que se ha trabajado se asienta en la idea de que la insurrección popular de 1952 supone el momento de consolidación hegemónica del NR asociado a las siglas del MNR. A su vez, esto implica asumir la muerte definitiva del Estado oligárquico burgués minero y terrateniente que, como se ha señalado, tiene su último halo de vida exitoso en la conspiración que desemboca en el asesinato de Villarroel. Para defender esta tesis es importante que se preste atención, por un lado, a los hechos que se celebran entre la muerte de Villarroel y la insurrección popular de abril de 1952 $\mathrm{y}$, por otro, a la vinculación de este último hecho con el rol jugado por el MNR y el resto de los actores políticos protagonistas del episodio referido.

El detonante del proceso revolucionario que se dio en Bolivia en abril de 1952 es, indudablemente, la convocatoria a una junta militar por parte de la oligarquía boliviana ante la victoria electoral del MNR en las elecciones de 1951. Dichas elecciones fueron convocadas ante la falsa idea de que la lucha nacional antioligárquica se había diluido durante el sexenio comprendido entre la muerte de Villarroel y las elecciones de 1951. Sin embargo, los hechos demostrarian lo contrario y el proletariado minero, que para entonces se había afirmado como vanguardia no solo del proletariado, sino del pueblo en general (Llobet, 1984, p.332), se convertiría en el actor protagonista por excelencia de la gesta revolucionaria. Debe tenerse en cuenta que, como señala Mayorga, "la revolución no fue la aplicación del programa electoral presentado por el MNR en 1951, sino el resultado de la movilización política de los actores populares cuya acción, sin embargo, se desplegó enmarcada en la hegemonía del nacionalismo

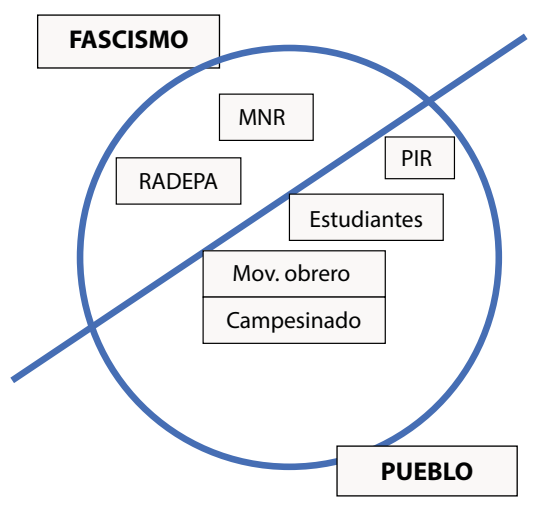

revolucionario" (Mayorga, 2003, p.242). En otras palabras, el nacionalismo revolucionario ya se había convertido en el marco discursivo hegemónico para las masas populares, lo que permitió el desplazamiento del MNR como protagonista de la gesta revolucionaria; pero, dado que no era posible desvincular la construcción hegemónica que ostentaba el nacionalismo revolucionario del MNR, fue este quien se hizo con el poder tras la insurrección. Este desplazamiento del protagonismo del MNR no debe entenderse como una lucha entre estos actores ya que, como se sostiene, el nacionalismo revolucionario está unido a las siglas del MNR. Por lo tanto, el alzamiento popular debe leerse como la consolidación del proyecto nacional popular del que forman parte amplios sectores sociales enfrentados a una oligarquía que se representa como la máxima expresión de la antinación, del antipueblo, y por ello que entre el proletariado minero y el MNR se pudo establecer una equivalencia de demandas, despojando a otros actores, como a las organizaciones de clase, de la posibilidad de dotar de sentido a la lucha política que se libraba contra la oligarquía.

Por otro lado, ténganse en consideración dos cuestiones importantes: en primer lugar, si la insurrección popular se da como respuesta al no reconocimiento de la victoria electoral por parte del MNR en las elecciones de 1951, se puede concluir que por aquel entonces ya existía un fuerte vínculo de identificación entre el proyecto político que defendía y representaba el MNR y las clases populares o subalternas que por entonces ya se habían constituido como sujetos políticos activos. En segundo lugar, se trataba de un proceso electoral en el que el voto universal no existía y, por tanto, quienes votaron al MNR no fueron los 
sectores populares y subalternos que más adelante protagonizaron la Revolución de 1952. Esto significa que el proyecto era extensible a otros sectores sociales; es decir, que las interpelaciones discursivas del MNR generaron procesos interclasistas de identificación. Por otro lado, si se tiene en cuenta, siguiendo a Zavaleta, que los comicios de 1951 eran convocados por la oligarquía, si esta "hubiese tenido confianza en el funcionamiento de su propia democracia y, en particular, en su control sobre el ejército, le habría resultado factible entregar el poder al vencedor" (Zavaleta, 1979, p.97) ya que habría podido conservar el control político desde la sombra. Sin embargo, prefirió no reconocer los resultados y encaramar al poder a una junta militar que desconoce todo procedimiento democrático. En otros términos, se puede afirmar que la actitud en la respuesta por parte de la oligarquía y sus aliados del ejército es la consecuencia de que la hegemonía oligárquica asumiera de forma implícita su crisis absoluta y consecuente derrumbe.

En conclusión, se defiende la tesis de que los tres días de lucha anteriores al 9 de abril de 1952 y la posterior victoria final contra el ejército pueden ser interpretados como el momento de consolidación de la hegemonía del nacionalismo revolucionario y el fin del estado oligárquico. Se trata, además, de una insurrección popular que no está liderada por ninguna organización, lo que pone en evidencia la espontaneidad de la gesta y que las clases populares se convierten en algo así como un emblema de la fuerza auténtica y legitima de la sociedad y la política boliviana. Asimismo, el éxito revolucionario supone el fracaso desplegado por parte del sistema oligárquico de intentar absorber y eliminar por la vía violenta el antagonismo que se había estado construyendo hasta entonces. Finalmente, siguiendo a Soage cuando plantea que "los mitos se convierten en imaginarios si tienen éxito en representar y movilizar a aquellos a quienes interpelan" (2006, p.56), la Revolución Nacional de 1952 se convirtió en el mito y en el imaginario de la nueva hegemonía. Esta afirmación tiene sentido en el marco del presente análisis, ya que se asume que la Revolución de 1952 se convierte en uno de los mitos fundacionales del nacionalismo revolucionario y en configurador del imaginario nacional popular, presentándose como "una ilusión de clausura del sistema de discurso” (p.56).

\section{Conclusiones}

El presente trabajo se ha aproximado desde una perspectiva discursiva y posestructuralista a la emergencia del Movimiento Nacionalista Revolucionario como un actor político capaz de articular, histórica y contingentemente, una serie de demandas particulares, lo que derivó en la construcción de una nueva formación hegemónica en Bolivia. El análisis se ha sustentado en la reflexión teórico política en torno al concepto hegemonía de corte posestructuralista. Asimismo, se ha llevado a cabo un delicado trabajo de contextualización histórica, para más adelante analizar en profundidad la emergencia del Movimiento Nacionalista Revolucionario y la posterior gesta revolucionaria de 1952, prestando atención no solo al MNR, sino también al rol jugado por el movimiento obrero minero. A partir todo esto, se desprenden las siguientes conclusiones.

La Guerra del Chaco es el episodio histórico que da inicio a un nuevo ciclo político en Bolivia, caracterizado por tres elementos centrales:

- Nuevo relato de nación: Las condiciones para construir un nuevo relato nacional vinieron dadas por la necesidad apremiante de un poder que convocara para la causa bélica a los sectores históricamente desplazados a posiciones subalternidad. Desde entonces, cualquier apelación a la nación debía incluir en su narrativa a quienes habían participado en la guerra, principalmente al movimiento obrero minero, al campesinado y a los jóvenes militares protagonistas de la contienda. Junto al empoderamiento de estos sujetos, emergieron nuevos significantes a disputar, tales como antioligarquía, sentido de lo nacional y popular y antiimperialismo.

- Pérdida de poder de la oligarquía minera: El empoderamiento político de estos nuevos sectores de la sociedad vino acompañado por el inicio de la decadencia del de la oligarquía o "rosca minera". La guerra supuso para la élite política y económica un momento de desorientación que derivó en su incapacidad para encarnar el nuevo proyecto político a construir tras la guerra.

- Nuevo umbral político: El nacionalismo revolucionario, expresado discursivamente en el "proyecto de llevar a cabo la revolución 
nacional", fue durante décadas el umbral a partir del cual se marcaron los límites desde donde fue posible tomar el poder de Bolivia. En otras palabras, el nacionalismo revolucionario, que se consolidó más adelante con el MNR, pasó a ser la matriz hegemónica, a partir de la cual los actores políticos, de derecha o de izquierda, democráticos o autoritarios, justificaron el ejercicio del poder político. $\mathrm{Y}$ es que, como se señaló más arriba, la consolidación hegemónica del nacionalismo revolucionario hizo que toda expresión política con aspiraciones de gobierno o de legitimidad estuviese enmarcada dentro del nacionalismo revolucionario: todo dentro del nacionalismo revolucionario, nada fuera de él.

En este contexto posbélico, y como respuesta a la crisis del Estado oligárquico, nacen una serie de formaciones políticas de diversa tradición trotskista, marxista, nacionalista y fascista, principalmente, entre ellas el Movimiento Nacionalista Revolucionario. Todas estas formaciones nacen a la luz del régimen que se derrumba y comparten entre ellas sus aspiraciones de interpelación popular y antioligárquica en un escenario de emergencia de nuevas demandas populares, principalmente del campesinado. Sin embargo, el MNR fue el partido que consiguió encarnar la necesidad de ruptura del orden social, al tiempo que construyó una frontera antagónica frente a la oligarquía, articulando las demandas de amplios sectores sociales, entre ellos el campesinado, sectores del ejército congregados en torno a RADEPA y el movimiento obrero (minero). En consecuencia, a diferencia del PIR, el POR o la FSB, el MNR construyó un proyecto político de carácter nacionalista e interclasista, caracterizado por englobar tendencias políticas tan dispares como el nacionalismo, socialismo, indigenismo, antiimperialismo o fascismo

La alianza del MNR con RADEPA, que derivó en el gobierno de Gualberto Villarroel, coincidió con un momento en el que los partidos de clase, en POR y principalmente el PIR, empezaron a perder su capacidad para representar las demandas de los sectores mineros. La pérdida de capacidad de interpelación de los partidos influyentes dio un giro a la hora de enarbolar sus propias consignas, pues se resignificaron con un sentido burgués e interclasista. Fue así como el MNR se hizo con los principales ejes de interpelación discursiva de los sectores obreros y populares.
Mientras por un lado el MNR, en su alianza con RADEPA, luchó por articular una frontera antagónica que identificara a la oligarquía minera como el elemento exterior constitutivo de una nueva subjetividad popular, diferentes sectores que se articularon como oposición al gobierno de Villarroel, entre ellos la misma oligarquía, también hicieron esfuerzos por construir una frontera antagónica frente a la alianza MNR-RADEPA. El Frente Antifascista, englobando principalmente a la vieja oligarquía y al PIR, nació asumiendo e identificando al gobierno de Villarroel como un gobierno fascista. En esta fortísima lucha por establecer una frontera antagónica dominante que representara al pueblo -oligarquía/pueblo vs. fascismo/pueblo-, la primera batalla la ganaron los sectores oligárquicos en alianza con la izquierda del PIR cuando consiguieron movilizar a sectores estudiantiles y populares, lo que derivó en la muerte de un presidente tan popular como Villarroel.

Esta pugna por establecer la frontera antagónica hegemónica se saldó con la insurrección popular de 1952, seis años después de la muerte de Villarroel. Para las elecciones de 1951, en las que resultó vencedor el MNR, el nacionalismo revolucionario ya estaba indudablemente vinculado a las siglas de este movimiento y las intentonas de convocar a una junta militar por parte de la élite oligárquica provocaron una movilización popular cuya acción se enmarcaba en las aspiraciones políticas del nacionalismo revolucionario. $\mathrm{El}$ alzamiento popular de 1952 debe leerse en una clave nacional y popular del que forman parte amplios sectores sociales enfrentados a una oligarquía que representa la máxima expresión de la antinación, del antipueblo.

La perspectiva teórica desde la que se trabajó en el presente artículo puede entenderse a la luz de una de las grandes contradicciones que para algunos pensadores del marxismo boliviano supuso comprobar por qué el movimiento obrero y las clases populares en general, en tanto protagonista del episodio revolucionario, no se hicieron con el poder político, sino que "se lo entregaron" al MNR, al que incluso consideraban como su partido de referencia. La respuesta a esta paradoja está en los postulados básicos sobre los que se asienta la perspectiva teórica recogida en el marco teórico; a saber, que todo orden social se estructura dentro de un discurso, y que no existen esencias o elementos subyacentes que expliquen lo social y que, por lo 
tanto, estén fuera del discurso. El alejamiento de una postura determinista o esencialista permite entender por qué existe una vinculación discursiva entre las clases populares que protagonizaron la insurrección de abril y el MNR. A la luz del análisis llevado a cabo, esta vinculación discursiva se asienta en la capacidad que tuvo el MNR para articular una serie de demandas que incluían aquellas que emergian de los sectores subalternos y que terminaron siendo representadas a través del nacionalismo revolucionario encarnado por este movimiento.

Finalmente, este trabajo entiende que el rol jugado porelMovimiento Nacionalista Revolucionario adquiere su dimensión nacional y popular como consecuencia de la precipitación de acontecimientos que se dan en Bolivia entre el nacimiento de movimiento -formación ecléctica ideológicamente y con aspiraciones de representación de una nueva burguesía urbana- y la Revolución de 1952. El carácter nacional y popular, caracterizado por un alto grado de compromiso a partir de 1952 con las aspiraciones de emancipación de amplios sectores sociales históricamente excluidos, tiene que ver con las oportunidades de articular discursivamente múltiples demandas sociales, lo que sienta las bases para la construcción de una nueva hegemonía política. Sin embargo, esto no quiere decir que los objetivos particulares del MNR fueran coincidentes con los del proletariado minero o campesinado. Al contrario, el MNR no dejó de ser una formación política orientada a defender y proteger los intereses de una nueva burguesía de carácter nacional que diese fin al Estado oligárquico. Lo realmente destacable de todo este proceso político es que sus aspiraciones antioligarquicas se hicieron coincidentes con las del proletariado minero y el campesinado tras un proceso de articulación discursiva que dotó al proyecto del MNR de un carácter popular. En definitiva, y de acuerdo con la perspectiva del análisis, la historia del MNR en el contexto de la Revolución de 1952 demuestra que toda hegemonía debe ser comprendida como la posibilidad de que una particularidad presente sus objetivos propios como aquellos que hacen posible la realización de los objetivos universales de una comunidad.

\section{Referencias}

Andrade, V. (1979). La revolución boliviana y los Estados Unidos (1944-1962). La Paz, Bolivia: Gisbert y Cía.

Antezana, L. (1983). Sistema y proceso ideológicos en Bolivia (1935-1979). In R. Zavaleta (Ed.), Bolivia, hoy. México D.F.: Siglo XXI.

Barrett, M. (2004). Ideología, política, hegemonía: de Gramsci a Laclau y Mouffe. In S. Žižek (Ed.), Ideología. Un mapa de la cuestión. Buenos Aires, Argentina: Fondo de Cultura Económica.

Barros, S. (2002). Orden, Democracia y Estabilidad. Discurso y politica en la Argentina entre 1976 y 1991. Córdoba, Argentina: Alción Editora.

Biglieri, P. (2011). El enfoque discursivo de la política: a propósito del debate sobre el pueblo como sujeto de una posible política emancipatoria. Laclau, Žižek y de Ipola. Debates y Combates, 1, 91-111.

Dunkerley, J. (1984). Rebellion in the Veins. Political Struggle in Bolivia, 1952-82. Londres, Inglaterra: Verso Editions.

Howarth, D. (2000). Discourse. Buckingham and Philadelphia: Open University Press.

Howarth, D. (2005). Aplicando la Teoría del Discurso: el Método de la Articulación. Studia Politicae, 5, 37-88. https://doi.org/10.22529/sp

Howarth, D., Norval, A., \& Stavrakakis, Y. (2000). Discourse Theory and Political Annalysis. Identities, Hegemonies and Social Change. Manchester and New York, USA: Manchester University Press.

Laclau, E. (2005). La razón populista. Buenos Aires, Argentina: Fondo de Cultura Económica.

Laclau, E. (2011). Identidad y hegemonía: el rol de la universalidad en la constitución de lógicas políticas. In J. Butler, E. Laclau, \& S. Žižek (Eds.), Contingencia,

hegemonía, universalidad. Diálogos contemporáneos en la izquierda. Buenos Aires, Argentina: Fondo de Cultura Económica.

Laclau, E. (2013). Argentina: anotaciones preliminares sobre los umbrales de la politica. Debates y Combates, (5).

Laclau, E., \& Mouffe, C. (2015). Hegemonía y estrategia socialista. Hacia una radicalización de la democracia. Madrid, España: Siglo XXI.

Llobet, C. (1984). Apuntes para una historia del movimiento obrero en Bolivia. In P. González Casanova (Ed.), Historia del movimiento obrero en América Latina. Colombia, Venezuela, Ecuador, Perú, Bolivia y Paraguay. México D.F.: Siglo XXI.

Lora, G. (1983). La clase obrera después de 1952. In R. Zavaleta (Ed.), Bolivia, hoy. México D.F.: Siglo XXI. 
Mayorga, J. F. (1985). El discurso del nacionalismo revolucionario. Cochabamba, Bolivia: Ediciones CIDRE.

Mayorga, J. F. (2003). La Revolución boliviana y la participación política. In PNUD / FES-ILDIS / PLURAL EDITORES (Ed.), Revoluciones del siglo XX. Homenaje a los 50 años de la Revolución Boliviana (Plural Edi). La Paz, Bolivia: Plural Editores.

Soage, A. (2006). La Teoría del Discurso de la Escuela de Essex en su contexto teórico. Circulo de Lingüistica Aplicada a La Comunicación, 25.

Zavaleta, R. (1979). Consideraciones generales sobre la historia de Bolivia (1932-1971). In P. González Casanova (Ed.), América Latina: historia de medio siglo. México D.F.: Siglo XXI. 